\title{
The phosphorylation status of insulin-like growth factor-binding protein-1 in prepubertal obese children
}

\author{
Tomohiro Kamoda, Hisako Saitoh, Satoko Nakahara ${ }^{1}$, Michiharu Inudoh ${ }^{1}$, Takeki Hirano ${ }^{2}$ and Akira Matsui \\ Department of Pediatrics, University of Tsukuba, Tsukuba, Japan, ${ }^{1}$ Department of Pediatrics, Kensei General Hospital, Iwase, Japan and \\ ${ }^{2}$ Department of Pediatrics, Ibaraki Children's Hospital, Ibaraki, Japan \\ (Correspondence should be addressed to T Kamoda, Department of Pediatrics, Institute of Clinical Medicine, University of Tsukuba, \\ 1-1-1 Tennoudai, Tsukuba 305, Ibaraki, Japan; Email: tkamoda@md.tsukuba.ac.jp)
}

\begin{abstract}
Objective: We measured the total and nonphosphorylated insulin-like growth factor-binding protein (IGFBP)-1 concentrations in obese children to determine the effect of obesity on the status of IGFBP-1 phosphorylation. We also measured the serum levels of insulin, total and free IGF-I, and IGFBP-3 to investigate their relationships to the IGFBP-1 phosphorylation status in obese subjects.

Subjects and methods: Nineteen prepubertal obese and 15 age-matched control children were included in the study. The serum levels of total and nonphosphorylated IGFBP-1 were determined by noncompetitive RIAs.

Results: The serum levels of total and nonphosphorylated IGFBP-1 were significantly lower in the obese group $(48.7 \pm 5.6 \mu \mathrm{g} / \mathrm{l}, P<0.001$ and $11.1 \pm 1.9 \mu \mathrm{g} / \mathrm{l}, P<0.01$ respectively) than in the controls $(86.7 \pm 9.0 \mu \mathrm{g} / \mathrm{l}$ and $28.8 \pm 6.2 \mu \mathrm{g} / \mathrm{l}$ respectively). However, the ratio of nonphosphorylated IGFBP-1 to total IGFBP-1 did not differ significantly between the obese and control groups. The circulating free IGF-I level was significantly higher in the obese children than in the controls $(P<0.05)$, while the serum levels of insulin, total IGF-I and IGFBP-3 were not significantly different between the two groups. A stepwise regression analysis of the combined group revealed that only the total IGFBP-1 level was an independent predictor of the free IGF-I concentration $(P<0.001)$.

Conclusion: The present study shows that both total and nonphosphorylated IGFBP-1 concentrations are decreased in obese children and the increased free IGF-I level in obese children is related to the reduced total IGFBP-1 level, but unrelated to the change in the IGFBP-1 phosphorylation status.
\end{abstract}

European Journal of Endocrinology 141 585-589

\section{Introduction}

Simple obesity is characterized by normal or accelerated growth in the presence of reduced levels of growth hormone $(\mathrm{GH})$ and poor $\mathrm{GH}$ responses to pharmacological stimuli (1-6). A recent study has suggested that suppression of the insulin-like growth factor-binding protein-1 (IGFBP-1) level due to hyperinsulinemia increases the level of free insulin-like growth factor-I (IGF-I) and promotes IGF-I's action, resulting in normal growth despite the reduced $\mathrm{GH}$ secretion in obese children (7). We have also reported that the serum IGFBP-1 level is suppressed in prepubertal obese children with fasting normoinsulinemia (8).

IGFBP-1, a peptide predominantly of hepatic origin, is one of the six binding proteins which regulate the bioactivity of IGF-I, and insulin directly suppresses production of IGFBP-1 in the liver (9). On the other hand, it is well known that changes in IGFBP-1's degree of phosphorylation alter its affinity for IGF-I and influence its modulatory effects on IGF-I's bioavailability
$(10,11)$. Adult serum contains mostly highly phosphorylated isoforms of IGFBP-1, while amniotic fluid and fetal and maternal sera have been reported to contain nonphosphorylated isoforms $(12,13)$. We speculated that the proportion of nonphosphorylated and phosphorylated forms of IGFBP-1 may influence the circulating free IGF-I level in obese children. To test this hypothesis, we investigated the effect of obesity on the IGFBP-1 phosphorylation status in prepubertal obese children.

\section{Subjects and methods}

\section{Subjects}

Nineteen Japanese children with simple obesity and 15 control children matched for age, sex and pubertal stage were included in the study. The characteristics of the subjects are shown in Table 1 . The control children were selected from the patients visiting the pediatric clinic 
Table 1 Characteristics of obese and control children. Values are the mean \pm S.E.M., with the ranges shown in parentheses.

\begin{tabular}{llcl}
\hline & $\begin{array}{c}\text { Obese } \\
(n=19)\end{array}$ & $\begin{array}{c}\text { Control } \\
(n=15)\end{array}$ & $\boldsymbol{P}$ value \\
\hline Age (years) & $8.3 \pm 0.3$ & $8.5 \pm 0.7$ & NS \\
& $(6.3-10.7)$ & $(6.1-11.6)$ & \\
Sex (M:F) & $10: 9$ & $8: 7$ & \\
BMI (kg/m $\left.{ }^{2}\right)$ & $24.6 \pm 0.5$ & $16.0 \pm 0.4$ & $<0.0001$ \\
& $(20.3-28.5)$ & $(13.3-18.5)$ & \\
\hline
\end{tabular}

NS: not significant.

because of nonendocrinological problems. The obese subjects were chosen from all children newly diagnosed as having simple obesity at the pediatric clinic of Tsukuba University Hospital. Both obese and control children were prepubertal (Tanner stage 1). The obese children who weighed $20 \%$ or more above the expected weight for age, sex and height, were diagnosed as having simple obesity with the absence of genetic or endocrinological abnormalities. With growth curve charts recorded from the children's birth, the onset of obesity was dated when the patient fulfilled the criteria for simple obesity mentioned above. The mean ( \pm s.E.M.) duration of obesity in the children studied was $5.1 \pm 0.4$ years. The obese and control children were all free of clinically or biochemically apparent disease and were not taking any medication. Informed consent was obtained from the parents of all the children and the study was approved by the local ethics committee.

\section{Methods}

Subjects were admitted to our hospital on the evening before the start of the study and were given a standard evening meal. Thereafter, only water was permitted. On the following morning, a blood sample was collected from each subject. Serum was separated immediately by centrifugation and kept at $-20^{\circ} \mathrm{C}$ until analysis.

\section{Hormone assays}

The serum level of total IGFBP-1 was determined with an RIA kit (Diagnostic System Laboratories, Inc., Webster, TX, USA) which is designed to eliminate differential antibody recognition of the various IGFBP-1 phosphoforms and is not affected by the status of IGFBP-1 phosphorylation (14). The lower limit of detection was $0.33 \mu \mathrm{g} / \mathrm{l}$, and the inter- and intraassay coefficients of variation were $3.5-6.0 \%$ and $2.7-5.2 \%$ respectively. The serum level of nonphosphorylated IGFBP-1 was measured by an RIA assay (Diagnostic System Laboratories) which recognized primarily a nonphosphorylated IGFBP-1 form without any reactivity to the highly phosphorylated isoforms (14). The minimum detectable limit was $0.2 \mu \mathrm{g} / \mathrm{l}$, and the inter- and intraassay coefficients of variation were $5.9-12.1 \%$ and $4.0-8.5 \%$ respectively. Serum IGFBP-3 was measured with an ELISA kit (Diagnostic System Laboratories). The lower limit of detection was $0.04 \mu \mathrm{g} /$ $\mathrm{l}$, and the inter- and intraassay coefficients of variation were $8.2-11.4 \%$ and $7.3-9.6 \%$ respectively.

The serum insulin level was determined with an RIA kit (Diagnostic Products Co., Los Angeles, CA, USA), with inter- and intraassay coefficients of variation of $4.9-10 \%$ and $2.5-6.5 \%$ respectively, and a lower limit of detection of $6 \mathrm{pmol} / \mathrm{l}$.

The free IGF-I concentration was measured by a highly sensitive two-site IRMA (Diagnostic System Laboratories). The lower limit of detection was $0.03 \mu \mathrm{g} / \mathrm{l}$, and the intra- and interassay coefficients of variation were $10.3 \%$ and $10.7 \%$ respectively. After acid-ethanol extraction, the total IGF-I concentration was assayed with an RIA kit (Medgenix Diagnostics Co., Brussels, Belgium). The sensitivity of this assay was $0.3 \mu \mathrm{g} / \mathrm{l}$, and the inter- and intraassay coefficients of variation were $3.6-6.4 \%$ and $2.0-6.4 \%$ respectively.

\section{Statistical analysis}

All results are expressed as the mean \pm S.E.M. unless otherwise stated. Student's unpaired t-test or the Mann-Whitney U test was used to determine statistical significance. Relationships between parameters were evaluated by linear regression analysis. Free IGF-I concentrations were log transformed prior to regression analysis. Furthermore, to investigate independent predictors of free IGF-I, a stepwise regression analysis was performed considering the variables age, gender, body mass index (BMI), nonphosphorylated IGFBP-1, the ratio of nonphosphorylated/total IGFBP1 , insulin, total IGF-I and IGFBP-3 values. All analyses were performed using Stat View 4.02 software (Abacus Concepts, Inc., Berkeley, CA, USA). Statistical significance was defined as a $P$ value of less than 0.05 .

\section{Results}

Table 2 shows the serum levels of total and nonphosphorylated IGFBP-1, the ratio of nonphosphorylated IGFBP-1 to total IGFBP-1, and the serum levels of insulin, total and free IGF-I and IGFBP-3 in the obese and control children. The total and nonphosphorylated IGFBP-1 concentrations were significantly lower in the obese group than in the controls. However, the ratio of nonphosphorylated IGFBP-1 to total IGFBP-1 did not differ significantly between the obese and control group $(22.9 \pm 2.3$ vs $30.4 \pm 4.7 \%)$. The total and nonphosphorylated IGFBP-1 levels correlated inversely with the fasting insulin level $(r=-0.40$, $P<0.05$ and $r=-0.47, P<0.01$ respectively) in the whole group. The circulating free IGF-I level was significantly higher in the obese children than in the controls $(P<0.05)$, while the serum levels of fasting 
Table 2 Mean serum concentrations of total and nonphosphorylated IGFBP-1, the ratio of nonphosphorylated/total IGFBP-1, and serum concentrations of insulin, total and free IGF-I and IGFBP-3 in obese and control children. Values are the mean \pm S.E.M.

\begin{tabular}{lccl}
\hline & $\begin{array}{c}\text { Obese } \\
(n=19)\end{array}$ & $\begin{array}{c}\text { Control } \\
(n=15)\end{array}$ & $\boldsymbol{P}$ value \\
\hline IGFBP-1 & & & \\
$\quad$ Total $(\mu \mathrm{g} / \mathrm{l})$ & $48.7 \pm 5.6$ & $86.7 \pm 9.0$ & $<0.001$ \\
$\quad$ Nonphosphorylated $(\mu \mathrm{g} / \mathrm{l})$ & $11.1 \pm 1.9$ & $28.8 \pm 6.2$ & $<0.01$ \\
$\quad$ Nonphosphorylated/total $(\%)$ & $22.9 \pm 2.3$ & $30.4 \pm 4.7$ & $\mathrm{NS}$ \\
Insulin $(\mathrm{pmol} / \mathrm{l})$ & $43.1 \pm 4.8$ & $31.4 \pm 4.9$ & $\mathrm{NS}$ \\
Total IGF-I $(\mu \mathrm{g} / \mathrm{l})$ & $193.1 \pm 12.8$ & $170.0 \pm 19.0$ & $\mathrm{NS}$ \\
Free IGF-I $(\mu \mathrm{g} / \mathrm{l})$ & $5.5 \pm 1.0$ & $3.0 \pm 0.6$ & $<0.05$ \\
IGFBP-3 $(\mu \mathrm{g} / \mathrm{l})$ & $6487 \pm 455$ & $5583 \pm 442$ & $\mathrm{NS}$ \\
\hline
\end{tabular}

NS: not significant.

insulin, total IGF-I and IGFBP-3 were not significantly different between the two groups. The serum levels of total and nonphosphorylated IGFBP-1 correlated inversely with $\log$ free IGF-I in the total subjects $(r=-0.59, P<0.001$; and $r=-0.52, P<0.01$ respectively) (Fig. 1). Furthermore, a stepwise regression analysis of the combined group revealed that only the total IGFBP-1 level was an independent predictor of the free IGF-I concentration $\left(\mathrm{R}^{2}=0.32, P<0.001\right)$.

\section{Discussion}

A number of reports have shown that IGFBP-1 is capable of inhibition as well as augmentation of IGF's bioactivity (15-17). These apparently paradoxical observations may be explained by the recent findings that differential phosphorylation at three serine residues can significantly alter IGFBP-1's affinity for IGFs (10). It has been demonstrated that nonphosphorylated IGFBP-1 has 4- to 6-fold lower affinity for IGF-I compared with a phosphorylated IGFBP-1 form, with phosphorylation occurring on serine residues 101 , 119 and 169 (10,11). A similar decrease in affinity is observed for purified nonphosphorylated versus phosphorylated IGFBP-1 in human amniotic fluid (13). These in vitro studies lead to the hypothesis that phosphorylation may have a regulatory role in modulating the effect of IGFBP-1 on IGF's action.

IGFBP-1 from cultures of human endometrial cells and human hepatoma cells has been shown to have one nonphosphorylated form and at least four phosphorylated isoforms which vary in their degree of phosphorylation $(10,18)$. Westwood et al. (12) have reported that IGFBP-1 normally circulates as a single, highly phosphorylated form in healthy adults and this is the form of IGFBP-1 usually secreted by the liver, whereas the status of IGFBP-1 phosphorylation can be altered, such as in pregnancy, where non- and lesser phosphorylated isoforms are present. They assumed that the increased level of nonphosphorylated IGFBP-1 in amniotic fluid, fetal serum, and maternal plasma during pregnancy may be responsible for the presence of a specific phosphatase which dephosphorylates

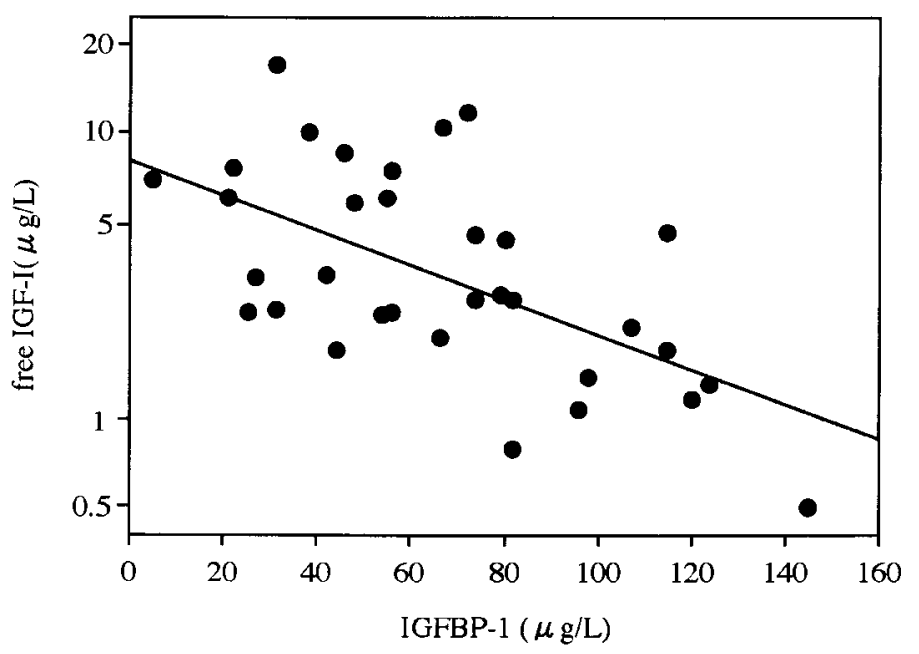

Figure 1 Relationship between the serum levels of IGFBP-1 and log free IGF-I in the total subjects $(r=-0.59, P<0.001)$. 
IGFBP-1. Furthermore, Martina et al. (19) examined IGFBP-1 phosphorylation profiles in the extraembryonic coelomic fluid of human gestation, in amniotic fluid and maternal serum throughout gestation, and in conditioned medium from explant cultures of maternal decidua, and suggested that the maternal decidua is the source of nonphosphorylated IGFBP-1 in these fluids in early gestation.

Khosravi et al. (14) developed novel noncompetitive ELISAs for total and nonphosphorylated IGFBP-1 using different detection antibodies, which are identical to the antibodies used in the respective RIA kits employed in our study. They measured total and nonphosphorylated IGFBP-1 concentrations in various biological fluids using the ELISAs and demonstrated that the median serum value of nonphosphorylated IGFBP-1 was 13-fold lower than that of total IGFBP-1 in healthy adults. In contrast, the mean ratio of nonphosphorylated to total IGFBP-1 was $30.4 \%$ in our control children, which was higher than that reported by Khosravi et al. Since the nonphosphorylated IGFBP-1 RIA kit detects not only nonphosphorylated IGFBP-1 but also lesser phosphorylated IGFBP-1 isoforms (14), we cannot exclude the possibility that prepubertal children may have higher serum levels of non- and/or lesser phosphorylated isoforms of IGFBP-1 compared with normal adults. On the other hand, Iwashita et al. (20) investigated the IGFBP-1 phosphorylation status in cord sera from normal term fetuses using anion exchange chromatography and showed that the mean ratio of nonphosphorylated to total IGFBP-1 was $34.8 \pm 3.9 \%$.

A recent study on the GH-IGF-I axis in obese subjects has suggested that suppression of the IGFBP-1 level due to hyperinsulinemia increases the level of free IGF-I and promotes IGF-I's action, resulting in normal growth despite the low GH secretion (7). Argente et al. (21) reported that prepubertal obese children were hyperinsulinemic and had significantly elevated serum free IGF-I and IGFBP-3 levels, whereas the level of IGFBP-1 was significantly decreased. On the other hand, Attia et al. (22) studied the GH-IGF-I axis in adolescent obesity, and their findings suggest that compensatory hyperinsulinemia and a low IGFBP-1 concentration may serve to increase the bioavailability of free IGF-I, which may, in turn, contribute to lower circulating GH, total IGF-I and IGFBP-3 concentrations. Our results showed that the total IGFBP-1 level was reduced and the circulating free IGF-I level was increased in obese children, and there was a significant inverse correlation between these two parameters in the whole group. Furthermore, a stepwise regression analysis of the combined group revealed that only the total IGFBP-1 level was an independent predictor of the free IGF-I concentration. In contrast, the fasting insulin, total IGF-I and IGFBP-3 concentrations were not significantly different between the obese and control group, but a significant inverse correlation was found between the serum levels of total IGFBP-1 and fasting insulin in the total subjects. We have previously reported that the serum IGFBP-1 level is suppressed in prepubertal obese children with fasting normoinsulinemia, suggesting that the integrated $24 \mathrm{~h}$ insulin release, which is not detected in the fasting state, may be responsible for the reduced IGFBP-1 level (8). Travers et al. (23) have also demonstrated that the IGFBP-1 level is more strongly related to insulin sensitivity than to the insulin level itself in early pubertal obese children.

The serum level of IGFBP-3 in obese subjects has been reported to be increased $(7,24,25)$ or unchanged (26). The IGFBP-3 concentration in our obese children was similar to that in controls. These discrepancies may be related to differences in sample selection or study design. It should be noted that circulating IGFBP-3 undergoes limited proteolysis, resulting in smaller molecular weight IGFBP-3 fragments which have lower affinity for IGF-I than the intact binding protein (27). However, it is not known whether IGFBP-3 proteolysis is increased in obese subjects.

We first hypothesized that an increase of the free IGF-I level in obese children may partly be explained by the change in the phosphorylation status of IGFBP-1 other than the reduced total IGFBP-1 level, since a nonphosphorylated isoform of IGFBP-1 has lower affinity for IGF-I compared with a highly phosphorylated form. Contrary to our expectation, the serum level of nonphosphorylated IGFBP-1 was lower in obese subjects than the controls and there was an inverse relationship between the level of nonphosphorylated IGFBP-1 and log free IGF-I in the total subjects, whereas a stepwise regression analysis revealed that the level of nonphosphorylated IGFBP-1 was not an independent predictor of the free IGF-I concentration. In addition, the ratio of nonphosphorylated to total IGFBP-1 did not differ significantly between the obese and control group and was also unrelated to the free IGF-I level. We, therefore, concluded that the phosphorylation status of IGFBP-1 cannot influence the free IGF-I level in obese children. Alternatively, the increased free IGF-I level in obese children was considered to be due to the reduced total IGFBP-1 level. On the other hand, Westwood et al. (28) investigated whether insulin can influence the phosphorylation status of IGFBP-1 in healthy adults, and they demonstrated that the status is not altered acutely in response to exogenous insulin, since only the highly phosphorylated isoforms of IGFBP-1 could be detected. Although the fasting insulin level did not differ significantly between the obese and control group in our study, it remains to be elucidated whether the IGFBP-1 phosphorylation status is influenced by chronic hyperinsulinemia.

In conclusion, the present study shows that both total and nonphosphorylated IGFBP-1 concentrations are decreased in obese children and the increased free IGF-I level in obese children is related to the reduced total IGFBP-1 level, but unrelated to the change in the IGFBP-1 phosphorylation status. 


\section{References}

1 Glass AR, Burmann KD, Dahms WT \& Boehm TM. Endocrine function in human obesity. Metabolism 198130 89-104.

2 Meistas MT, Foster GV, Margolis S \& Kowarski AA. Integrated concentrations of growth hormone, insulin, C-peptide and prolactin in human obesity. Metabolism 198231 1224-1228.

3 Jung RT, Campbell RG, James WPT \& Callingham BA. Altered hypothalamic and sympathetic responses to hypoglycemia in familial obesity. Lancet 19821 1043-1046.

4 Kopelman PG \& Noonan K. Growth hormone response to low dose intravenous injections of growth hormone releasing factor in obese and normal weight women. Clinical Endocrinology 1986 24 157-164.

5 Vignolo M, Naselli A, Di Battista E, Mostert M \& Aicardi G. Growth and development in simple obesity. European Journal of Pediatrics $1988147242-244$

6 Vanderschueren-Lodeweyckx M. The effect of simple obesity on growth and growth hormone. Hormone Research 199340 23-30.

7 Frystyk J, Vestbo E, Skjærbæk C, Mogensen CE \& Ørskov H. Free insulin-like growth factors in human obesity. Metabolism 199544 $37-44$.

8 Saitoh H, Kamoda T, Nakahara S, Hirano T \& Nakamura N. Serum concentrations of insulin, insulin-like growth factor (IGF)-I, IGF binding protein (IGFBP)-1 and -3 and growth hormone binding protein in obese children: fasting IGFBP-1 is suppressed in normoinsulinaemic obese children. Clinical Endocrinology 199848 487-492.

9 Lee PDK, Giudice LC, Conover, CA \& Powell DR. Insulin-like growth factor binding protein-1: recent findings and new directions. Proceedings of Society for Experimental Biology and Medicine 1997216 319-357.

10 Jones JI, D’Ercole AJ, Camacho-Hubner C \& Clemmons DR. Phosphorylation of insulin-like growth factor (IGF)-binding protein 1 in cell culture and in vivo: effects on affinity for IGF-I. Proceedings of the National Academy of Sciences of the USA 199188 7481-7485.

11 Jones JI, Busby WH, Wright G, Smith CE, Kimack NM \& Clemmons DR. Identification of the sites of phosphorylation in insulin-like growth factor binding protein-1. Regulation of its affinity by phosphorylation of serine 101. Journal of Biological Chemistry 1993268 1125-1131.

12 Westwood M, Gibson JM, Davies AJ, Young RJ \& White A. The phosphorylation pattern of insulin-like growth factor-binding protein-1 in normal plasma is different from that in amniotic fluid and changes during pregnancy. Journal of Clinical Endocrinology and Metabolism 199479 1735-1741.

13 Koistinen R, Angervo M, Leinonen P. Hakala T \& Seppälä M. Phosphorylation of insulin-like growth factor-binding protein-1 increases in human amniotic fluid and decidua from early to late pregnancy. Clinica Chimica Acta 1993215 189-199.

14 Khosravi MJ, Diamandi A \& Mistry J. Immunoassay of insulin-like growth factor binding protein-1. Clinical Chemistry 199743 $523-532$.

15 Liu L, Brinkman A, Blot C \& Harel L. IGFBP-1, an insulin-like growth factor binding protein is a cell growth inhibitor. Biochemical and Biophysical Research Communications 1991174 673-679.

16 Elgin RG, Busby WH \& Clemmons DR. An insulin-like growth factor (IGF) binding protein enhances the biologic response to
IGF-I. Proceedings of the National Academy of Sciences of the USA $1987843254-3258$.

17 Busby WH, Klapper DG \& Clemmons DR. Purification of a 31000 -dalton insulin-like growth factor binding protein from amniotic fluid. Journal of Biological Chemistry 1988263 14203-14210.

18 Frost RA \& Tseng L. Insulin-like growth factor-binding protein-1 is phosphorylated by cultured human endometrial stromal cells and multiple protein kinases in vitro. Journal of Biological Chemistry $199126618082-18088$.

19 Martina NA, Kim E, Chitkara U, Wathen NC, Chard T \& Guidice LC. Gestational age-dependent expression of insulin-like growth factor-binding protein-1 (IGFBP-1) phosphoisoforms in human extraembryonic cavities, maternal serum, and decidua suggests decidua as the primary source of IGFBP-1 in these fluids during early pregnancy. Journal of Clinical Endocrinology and Metabolism 199782 1894-1898.

20 Iwashita M, Sakai K, Kudo Y \& Takeda Y. Physiological significance of insulin-like growth factor (IGF)-binding protein-1 (IGFBP-1) phosphoisoforms in fetal growth. Clinical Pediatric Endocrinology 19987 (Suppl 11) 31-37.

21 Argente J, Caballo N, Barrios V, Pozo J, Munoz MT, Chowen JA et al. Multiple endocrine abnormalities of the growth hormone and insulin-like growth factor axis in prepubertal children with exogenous obesity: effect of short- and long-term weight reduction. Journal of Clinical Endocrinology and Metabolism 1997 $822076-2083$.

22 Attia N, Tamborlane WV, Heptulla R, Maggs D, Grozman A, Sherwin RS et al. The metabolic syndrome and insulin-like growth factor regulation in adolescent obesity. Journal of Clinical Endocrinology and Metabolism 199883 1467-1471.

23 Travers SH, Labarta JI, Gargosky SE, Rosenfeld RG, Jeffers BW \& Eckel RH. Insulin-like growth factor binding protein-1 levels are strongly associated with insulin sensitivity and obesity in early pubertal children. Journal of Clinical Endocrinology and Metabolism $1998831935-1939$.

24 Slowinska-Srzednicka J, Zgliczynski W, Makowska A, Jeske W, Brzezinska A, Soszynski P et al. An abnormality of the growth hormone/insulin-like growth factor-I axis in women with polycystic ovary syndrome due to coexistent obesity. Journal of Clinical Endocrinology and Metabolism 199274 1432-1435.

25 Cordido F, Casanueva FF, Vidal JI \& Dieguez C. Study of insulin-like growth factor I in human obesity. Hormone Research 199136 187-191.

26 Nam SY, Lee EJ, Kim KR, Cha BS, Song YD, Lim SK et al. Effects of obesity on total and free insulin-like growth factor (IGF)-1, and their relationship to IGF-binding protein (BP)-1, IGFBP-2, IGFBP-3, insulin, and growth hormone. International Journal of Obesity and Related Metabolic Disorders 199721 355-359.

27 Blat C, Villaudy J \& Binoux M. In vivo proteolysis of serum insulinlike growth factor (IGF) binding protein-3 results in increased availability of IGF to target cells. Journal of Clinical Investigation $1994932286-2290$.

28 Westwood M, Gibson JM, Williams AC, Clayton PE, Hamberg O, Flyvbjerg A et al. Hormonal regulation of circulating insulin-like growth factor-binding protein-1 phosphorylation status. Journal of Clinical Endocrinology and Metabolism 199580 3520-3527.

Received 10 February 1999

Accepted 3 August 1999 